\title{
2020 Corrections
}

\section{Erratum}

To the article "Protatranes as synthetic malting biostimulants" by S. N. Adamovich and E. N. Oborina, Vol. 69, No. 1, pp. 179-181, January, 2020.

In the original international version of the article, the first Project No. was specified incorrectly.

In should be

"This work was financially supported by the Russian foundation for Basic Research and the Government of the Irkutsk Region (Project Nos 20-43-380001 and 20-016-00114)." 